\title{
Hipertansiyon Hastası Yaşlı Bireylerde DASH Diyetine Uyumun Kan Basıncı, Antropometrik Ölçümler ve Diyet Alımı Üzerine Etkisi
}

\author{
The Effect of Adherence to DASH Diet on Blood Pressure, Anthropometric Measurements and \\ Dietary Intakes in Elderly Hypertension Patients
}

\author{
Bilgin Karaosman ${ }^{1}$, Müjgan Öztürk ${ }^{2}$
}

Geliş tarihi/Received: 10.07.2019 • Kabul tarihi/Accepted: 29.08.2019

\section{ÖZET}

Amaç: Bu araştırmada, Kuzey Kıbrıs Türk Cumhuriyeti’nde bir sağlık merkezine kayıtlı yaşlı hipertansiyon hastalarında, 'Hipertansiyonu Önlemek için Diyet Yaklaşımları'na (Dietary Approaches to Stop Hypertension DASH) uyumun kan basıncı, antropometrik ölçümler ve diyetle alım üzerine etkilerinin değerlendirilmesi amaçlanmıştır.

Bireyler ve Yöntem: Araştırmaya 60 yaş üzeri 133 hipertansiyon hastası (\%18 erkek) dahil edilmiştir. Hastaların boy uzunluğu, vücut ağırlığı, bel çevresi, sistolik (SKB) ve diyastolik kan basıncı (DKB) ölçülmüştür. Hastaların diyetle alımını değerlendirmek için 24 saatlik geriye dönük besin tüketim kaydı alınmıştır. Bireylerin DASH diyetine uyumu 'düşük uyum: $<4$ puan’ ve ‘yüksek uyum: $\geq 4$ puan' şeklinde değerlendirilmiştir.

Bulgular: DASH skoru 3.1£0.8 ve DASH diyetine yüksek uyum gösteren bireylerin oranı \%19.5’tir. DASH diyetine düşük ve yüksek uyum gösteren bireylerin SKB ve DKB değerleri arasında anlamlı bir farklılık bulunmamıştır ( $p>0.05$ ). Hem beden kütle indeksi, hem de kardiyovasküler risk faktörlerinden biri olan bel/boy oranının her iki grup arasında benzer olduğu görülmüştür (p>0.05). DASH diyetine yüksek uyum gösteren bireylerde, düşük uyum gösteren bireylere göre sebze ve süt ürünleri gruplarının tüketim miktarları tüm bireylerde daha yüksek, meyve tüketimi yalnızca kadın bireylerde yüksek ve şeker tüketimi tüm bireylerde daha düşük bulunmuştur ( $\mathrm{p}<0.05)$. Erkeklerde, DASH diyetine yüksek uyum gösteren bireylerin posa, $B_{2}$ vitamini, folik asit, potasyum, magnezyum ve çinko alımının; kadınlarda ise $B_{2}$ vitamini, folik asit, $C$ vitamini, potasyum, magnezyum, kalsiyum ve fosfor alımının düşük uyum gösteren gruptan anlamlı olarak yüksek olduğu saptanmıştır ( $\mathrm{p}$ <.05). Hem erkek hem de kadınlarda sodyum alımı yüksek uyum gösteren grupta anlamlı olarak daha düşük bulunmuştur $(\mathrm{p}<0.05)$.

Sonuç: Hipertansiyon hastası yaşlı bireylerde DASH diyetine yüksek uyumun kan basıncına olumlu etkisinin olmadığı ancak vücut ağırlığında artışın DKB düzeyinde artışla ilişkili olduğu görülmüştür. Bu hasta grubunda diyete uyumun genel olarak düşük olmasının, DASH diyetinin olumlu etki gösterememiş olmasında rolü olabileceği düşünülmektedir.

Anahtar kelimeler: Hipertansiyon, DASH diyeti, besin ögesi, antropometrik ölçümler

1. Doğu Akdeniz Üniversitesi, Sağllk Bilimleri Fakültesi, Beslenme ve Diyetetik Bölümü, Gazimağusa, Kuzey Kubrıs Türk Cumhuriyeti

(ㄱ) https://orcid.org/0000-0002-8661-8930

2. İletişim/Correspondence: Doğu Akdeniz Üniversitesi, Sağlık Bilimleri Fakültesi, Beslenme ve Diyetetik Bölümü, Gazimağusa, Kuzey Kıbrıs Türk Cumhuriyeti E-posta: mujgan_ozturk@yahoo.com • ○ https://orcid.org/0000-0003-1736-7960 


\section{ABSTRACT}

Aim: The aim of this study was to evaluate the effects of adherence to Dietary Approaches to Stop Hypertension (DASH) diet on blood pressure, anthropometric measurements and dietary intakes of elderly hypertension patients, who were admitted to a public health centre in Turkish Republic of Northern Cyprus.

Subjects and Method: Study was held on 133 hypertensive patients over 60 years of age (18\% men). Height, body weight, waist circumference, systolic blood pressure (SBP) and diastolic blood pressure (DBP) were measured. Dietary intakes were determined by using 24 -hour dietary recall. Adherence to DASH diet was evaluated as follows: " $<4$ points: low adherence" and " $\geq 4$ points: high adherence".

Results: Mean DASH score was 3.1 \pm 0.8 , and $19.5 \%$ of subjects were classified as high adherent to DASH diet. No significant difference was found between SBP and DBP values of patients with a low or high adherence to DASH diet ( $>>0.05)$. Both body mass index (BMI) and waist to height ratio, as one of the main cardiovascular risk factors, were found similar between groups ( $p>0.05$ ). The group with high adherence had significantly higher vegetable and dairy consumption and lower sugar consumption as compared to low adherence group, while the fruit consumption was only significantly higher in women $(p<0.05)$. It was found that men with high adherence had statistically significant higher intakes of fiber, vitamin $B_{2}$, folic acid, potassium, magnesium and zinc, while women had statistically significant higher intakes of vitamin $\mathrm{B}_{2}$, folic acid, vitamin C, potassium, magnesium, calcium and phosphorus. Both men and women had lower consumption of sodium in high adherence group than low adherent subjects $(\mathrm{p}<0.05)$.

Conclusion: It was found that high adherence to DASH diet had no effect on blood pressure, however an increase in body weight was associated with an increase in DBP level. The general tendency of a low adherence to DASH diet in this population may have a role in the lack of positive effects.

Keywords: Hypertension, DASH diet, nutrients, anthropometric measurements

\section{GíRIŞ}

Dünya Sağlık Örgütü (DSÖ) yaşlanmayı biyolojik olarak hücresel ve moleküler düzeyde zaman içerisinde biriken hasarın, fiziksel ve mental kapasitede düşüşe neden olarak ölümle sonuçlanması şeklinde tanımlamaktadır (1). Yaşlılık sürecinde vücut bileşimi ve organların işlevlerinde oluşan değişiklikler yaşlının besin alımı, besin ögelerinin sindirimi ve metabolizmasını etkileyerek, sağlık sorunlarının ortaya çıkışını kolaylaştırır (2). Artmış kan basıncı küresel mortalitenin önde gelen nedenlerinden biri olup 2010 yılında 9.4 milyon kişinin ölümüne neden olduğu görülmüştür (3). Dünya Sağlık Örgütü’nün (DSÖ) 2014 yllı verilerine göre dünyada 18 yaş ve üzeri yetişkinlerde hipertansiyon prevalansı \%22.0'dir (3). Ülkemizde 2017 yılında yapılan Türkiye'de “Türkiye Bulaşıcı Olmayan Hastalıkların Prevalansı Hanehalkı Sağlık Araştırması" verilerine göre hipertansiyon prevelansı \%26.1'dir (4).
Beslenme temelli yaklaşımlar hipertansiyonun önlenmesinde ve Evre 1 hipertansiyonu olan bireylerde kan basincının düzenlenmesinde birinci basamak tedavi olarak önerilmektedir. 'Hipertansiyonu Önlemek için Diyet Yaklaşımları' (Dietary Approaches to Stop Hypertension, DASH) hipertansiyonun önlenmesi ve tedavisinde etkinliği pek çok çalışma ile gösterilmiş olan beslenme örüntülerinden biridir (5-7). DASH diyetinde tam tahıllı ürünler, sebze ve meyveler, düşük yağlı süt ve süt ürünleri, yağsız kırmızı et, tavuk eti, balık eti ile yağlı tohumlar ve kuru baklagillerin tüketilmesi önerilmektedir. DASH diyeti toplam yağ, doymuş yağ ve kolesterol alımının sinırlandırıldığı; potasyum, magnezyum, kalsiyum ve diyet posası bakımından zengin bir örüntü oluşturmaktadır $(8,9)$.

Her ne kadar DASH diyetinin sağlık üzerindeki olumlu etkileri bilinse de tedavi altındaki yaşlı hipertansiyon 
hastalarının DASH diyetine uyumu ile ilgili çalışma sayısı azdır. $\mathrm{Bu}$ nedenle bu çalışmanın amacı, 60 yaş ve üzeri hipertansiyon hastası bireylerin DASH diyetine uyumlarmı belirlemek ve diyete uyumun antropometrik ölçümler, diyet alımları ve kan basıncı üzerine etkisini değerlendirmektir.

\section{BİREYLER VE YÖNTEM}

Araştırmanın evrenini Kuzey Kıbrıs Türk Cumhuriyeti (KKTC) Güzelyurt Sağlık Merkezi’ne kayıtlı, hekim tarafından hipertansiyon tanısı almış, 60 yaş ve üzeri 201 birey oluşturmuştur. Alzheimer veya demansı bulunan, iletişim engeli olan, antropometrik ölçümlerin alınmasında engel teşkil edecek rahatsızlığı olan bireyler araştırmaya dahil edilmemiştir. MayısEkim 2015 tarihleri arasında tüm evrene ulaşılması hedeflenen çalışmada 145 bireye ulaşılmış, ulaşılan hastalardan 4 kişinin görüşmeyi kabul etmemesi, 5 kişi ile sağlıklı iletişim kurulamaması ve 3 kişinin görüşmeyi yarıda bırakması nedeniyle toplam 133 hipertansiyon hastası ile (\%18'i erkek ve \%82'si kadın) çalışma tamamlanmıştır. Hemşire ekibi eşliğinde ev ziyareti yapılarak hastalar ile yüz yüze görüşülmüştür.

Araştırma kapsamında uygulanan anket formu beş bölümden oluşmaktadır. Formun birinci bölümünde sosyo-demografik özellikleri saptamaya yönelik sorular yer almıştır. İkinci bölümde boy uzunluğu, vücut ağırlığı, bel çevresi araştırmacı tarafından; sistolikkanbasıncı(SKB)vediyastolikkanbasincı(DKB) ölçümleri ise sağlık merkezinde görevli hemşireler tarafından valide edilmiş bir civa sfigmomanometre ile 3-5 dakikalık dinlenme halinde oturur pozisyonda ölçülerek kayıt edilmiştir (10). Beden kütle indeksi (BKI) ve bel/boy oranı araştırmacı tarafından hesaplanmıştır. Bel çevresi için kardiyovasküler hastalıklar, diyabet ve hipertansiyon riski için kesim noktası olarak erkeklerde $\geq 102 \mathrm{~cm}$, kadınlarda ise $\geq 88$ cm (11), bel/boy oranı için ise optimal kesim noktası olarak 0.55 kabul edilmiştir (12). Üçüncü bölümde katılımcıların hastalık, ilaç kullanımı, sigara ve alkol alışkanlıkları, fiziksel aktivite yapma durumu, diyet uygulama durumları ve sofra tuzu kullanımlarına yönelik sorular yer almıştır. Anket formunun dördüncü bölümünde 24-saatlik geriye dönük besin tüketim kaydı formu yer almıştır. Bireylerden besin tüketimi alınırken porsiyon ölçüsünde hata olmaması açısından fotoğraflı besin kataloğundan yararlanılmıştır (13). Tüketilen besinlerin miktarı saptandıktan sonra, Beslenme Bilgi Sistemleri Paket Programı (BEBİS) 7.0 temel versiyonu kullanılarak enerji, makro ve mikro besin ögeleri alımları günlük bazda saptanmıştır (14). Anketin son bölümünde ise katılımclların diyet örüntülerinin, DASH diyetine uyumu değerlendirilmiştir. DASH skorlaması, Casanova et al. (15)'un araştırması doğrultusunda hedef porsiyon miktarlarının farklı olması nedeniyle 4 farklı enerji alımına göre (1600, 2000, 2600 ve 3100 kkal/gün) ayrı olarak hesaplanmıştır. Bireyin tüketim miktarı belirtilen porsiyonun altında ise ' 0 ', kısmen yakın ise ' 0.5 ' ve önerilen porsiyon miktarı kadar veya üzerinde ise ' 1 ' puan verilmiştir. Düşük miktarda tüketilmesi istenilen besin gruplarında (yağlar, tatlllar, şeker ve şeker içeren içecekler) ise normal skorlamanın tersi yönünde hesaplama yapılmıştır. Puanlama sonrası ulaşlabilen en yüksek skor 8'dir (DASH diyetine tam uyum) (15). Kullanılan ölçeğin bir kesim noktası olmamakla birlikte farklı çalışmalarda medyan ya da ölçeğin tam orta puanı kesim noktası olarak kullanılmıştır (15-17). Bu çalışmada ölçeğin tam orta puanı olan “4” değeri kesim noktası olarak kullanılmış ve bireyler "düşük uyum gösteren <4 puan” ve "yüksek uyum gösteren $\geq 4$ puan” şeklinde değerlendirilmiştir $(16,17)$.

Doğu Akdeniz Üniversitesi Etik Kurulu tarafından 2016/21-02 No’lu kararı ile araştırmanın etik açıdan uygun olduğu bulunmuştur. Çalışmaya katılmayı kabul eden tüm katılımcılara "Aydınlatılmış Onam Formu” okutulup imzalatılmıştır. $\mathrm{Bu}$ araştırmanın yapılabilmesi için Güzelyurt Kaymakamlığı'ndan 4 Mayıs 2015 tarih ve MYB.4.00-02/04-15/584 sayılı yazıyla ve 17 Nisan 2015 tarih SAB.0.00-5/75/915/973 sayı ile KKTC Sağlık Bakanlığı'ndan ve DASH skorlaması için ilgili araştırmacıdan (15) izin alınmıştır. 


\section{Verilerin İstatistiksel Değerlendirmesi}

Veriler elektronik ortama aktarıldıktan sonra Sosyal Bilimler için İstatistik Paket Programı (Statistical Package for Social Science, SPSS, versiyon 19.0) kullanılarak analiz edilmiştir. DASH diyetine yüksek uyum gösteren gruptaki kişi sayısının 30'un altında olması nedeniyle parametrik olmayan testler kullanılmıştır. Bağımsız değişkenin iki kategoriden oluşması halinde (cinsiyet, sofra tuzu kullanımı, DASH diyetine uyum vb.) Mann Whitney U testi, kategorik değişkenlerin değerlendirilmesinde ise Fisher'in kesin ki-kare testi kullanılmıştır. İki nicel değişken arasındaki korelasyonun saptanmasında Spearman korelasyon testi kullanılmıştır. Tüm testler için $\mathrm{p}<0.05$ anlamlı olarak kabul edilmiştir.

\section{BULGULAR}

Araştırmaya katılan 133 hipertansiyon hastası bireyin \%18'i erkek ve \%82'si kadın olup, yaş ortalamaları sirasıly $79.3 \pm 6.6$ ve $76.8 \pm 8.4$ yıldır. Bireylerin \%51.1'inin okur yazar olmadığı, \%36.1'inin ise ilkokul mezunu olduğu görülmüştür. Bireylerin \%41.4'ünde diyabet, \%40.6'sında hiperkolesterolemi ve \%30.8'inde kardiyovasküler hastalık mevcuttur. Tüm katılımcılar düzenli olarak hipertansiyon ilacı kullandıklarını belirtmiştir. Çalışmada alkol kullanan birey bulunmadığı ve hastaların yalnızca \%7.5’inin sigara kullandığı belirlenmiştir. Bireylerin \%98.5'i düzenli olarak fiziksel aktivite yapmadığını belirtirken, yalnızca \%3.0’ünün hastalıklarına yönelik önerilen diyet programlarını uyguladıkları saptanmıştır (veriler tabloda gösterilmemiştir).

Bireylerin \%96.2'sidüzenliolarak3 ana öğüntükettiğini belirtmiştir. Katılımcıların \%21.8'inin yemeklerin tadına bakmadan tuz eklediği saptanmıştır. Yemeklerin tadina bakmadan tuz ekleyen bireylerin ortalama DKB değeri $(81.7 \pm 10.0 \mathrm{mmHg})$, tuz atmayan bireylere $(77.2 \pm 10.8 \mathrm{mmHg})$ göre anlaml olarak yüksek olup, $(\mathrm{p}<0.05)$, SKB değerleri arasında ise istatistiksel olarak anlamlı bir fark bulunmamıştır $\left(\mathrm{SKB}_{\text {tuz atan }}: 138.8 \pm 21.3 \mathrm{mmHg}, \mathrm{SKB}_{\text {tuz atmayan }}: 132.2 \pm 18.1\right.$ mmHg) ( $p>0.05)$ (veriler tabloda gösterilmemiştir).

Bireylerin DASH skorları ortalaması $3.1 \pm 0.8$ olarak bulunmuş ve yalnızca \%19.5'inin DASH diyetine yüksek uyum gösterdiği saptanmıştır (tabloda gösterilmemiştir). DASH diyetine düşük ve yüksek uyum gösteren gruplar arasında SKB, DKB, BKİ ve bel boy oranları arasında fark olmadığı belirlenmiştir (p>0.05) (Tablo 1).

Bel çevresi ve bel/boy oranı risk sinıflamasına göre DASH diyetine yüksek ya da düşük uyum gösteren gruplar arasında istatistiksel olarak anlamlı bir fark yoktur ( $\mathrm{p}>0.05)$ (T ablo 2).

Kadın ve erkek bireylerde vücut ağırlığının yalnızca DKB ile pozitif ilişkili olduğu ( $\mathrm{p}<0.05)$, BKİnin ise kan basıncı ile ilişkili olmadığı bulunmuştur (Tablo 3).

DASH skoru ve besin gruplarından tüketim miktarları arasındaki ilişki incelendiğinde; DASH diyetine yüksek uyum gösteren tüm bireylerin sebze ve süt ürünleri tüketiminin, düşük uyum

Tablo 1. DASH diyetine uyum sınıflamasına göre SKB ve DKB ile bazı antropometrik ölçümlerin karşılaştırılması

\begin{tabular}{llccccccc}
\hline Kan Basinc1 & DASH Diyetine Uyum & S & Alt & Üst & $\bar{X}$ & SS & Ortanca & $p$ \\
\hline \multirow{2}{*}{ SKB } & Düşük uyum & 107 & 98.0 & 210.0 & 133.6 & 19.6 & 130.0 & \multirow{2}{*}{0.58} \\
& Yüksek uyum & 26 & 100.0 & 160.0 & 133.9 & 16.3 & 140.0 & \\
DKB & Düşük uyum & 107 & 51.0 & 100.0 & 78.2 & 10.5 & 80.0 & 0.75 \\
& Yüksek uyum & 26 & 46.0 & 90.0 & 78.0 & 11.9 & 80.0 & \\
\multirow{2}{*}{ BKİ } & Düşük uyum & 107 & 20.2 & 57.9 & 32.4 & 6.96 & 30.4 & 0.35 \\
& Yüksek uyum & 26 & 22.9 & 37.5 & 30.3 & 4.25 & 30.2 & \\
\multirow{2}{*}{ Bel/Boy } & Düşük uyum & 107 & 0.50 & 1.01 & 0.70 & 0.09 & 0.69 & 0.59 \\
& Yüksek uyum & 26 & 0.55 & 0.91 & 0.69 & 0.07 & 0.68 & 0.59 \\
\hline
\end{tabular}

Mann Whitney U Testi

BKI: Beden kütle indeksi, SKB: Sistolik kan basınc, DKB: Diastolik kan basincl. 
Tablo 2. Katılımcıların DASH diyetine uyumlarına göre antropometrik ölçümlerinin karşılaştırılması

\begin{tabular}{|c|c|c|c|c|c|c|c|}
\hline \multirow{2}{*}{$\begin{array}{l}\text { Antropometrik ölçümler ve } \\
\text { KVH riski kesim noktaları }\end{array}$} & \multicolumn{2}{|c|}{ Düşük Uyum } & \multicolumn{2}{|c|}{ Yüksek Uyum } & \multicolumn{2}{|c|}{ Toplam } & \multirow{2}{*}{$p$} \\
\hline & $S$ & $\%$ & S & $\%$ & $\mathbf{S}$ & $\%$ & \\
\hline \multicolumn{8}{|l|}{ Bel çevresi (cm) } \\
\hline $\mathrm{E}<102, \mathrm{~K}<88$ & 13 & 92.9 & 1 & 7.1 & 14 & 100.0 & \multirow{2}{*}{0.19} \\
\hline$E \geq 102, K \geq 88$ & 94 & 79.0 & 25 & 21.0 & 119 & 100.0 & \\
\hline \multicolumn{8}{|l|}{ Bel/boy oranı } \\
\hline$<0.55$ & 4 & 100.0 & - & - & 4 & 100.0 & \multirow{2}{*}{0.41} \\
\hline$\geq 0.55$ & 103 & 79.8 & 26 & 20.2 & 129 & 100.0 & \\
\hline
\end{tabular}

Fisher Kesin Ki kare Testi

DASH: Hipertansiyonu Önlemek için Diyet Yaklaşımları (Dietary Approaches to Stop Hypertension), E: Erkek, K: Kadın, KVH: Kardiyovasküler hastallk.

Tablo 3. Katılımcıların vücut ağırlığı ve BKİ ile kan basıncı arasındaki ilişki

\begin{tabular}{llllll}
\hline & & \multicolumn{2}{c}{ Kadın (n=109) } & \multicolumn{2}{c}{ Erkek (n=24) } \\
\cline { 2 - 5 } & & SKB & DKB & SKB & DKB \\
\hline \multirow{2}{*}{ Vücut ağırlığı $(\mathrm{kg})$} & $r$ & 0.18 & 0.20 & 0.32 & 0.51 \\
& $p$ & 0.06 & 0.04 & 0.12 & 0.01 \\
\multirow{2}{*}{ BKİ $\left(\mathrm{kg} / \mathrm{m}^{2}\right)$} & $r$ & 0.15 & 0.13 & 0.22 & 0.41 \\
& $p$ & 0.13 & 0.17 & 0.29 & 0.06 \\
\hline
\end{tabular}

Spearman Korelasyon Testi

BKI: Beden kütle indeksi, SKB: Sistolik kan basıncı, DKB: Diastolik kan basıncı

gösteren bireylerden yüksek, şeker tüketiminin ise düşük olduğu saptanmıştır ( $\mathrm{p}<0.05)$ (Tablo 4). Kadın bireylerde meyve tüketiminin yüksek uyum gösteren grupta, düşük uyum gösteren gruba göre yüksek olduğu görülmüştür ( $p<0.05)$.

DASH diyetine uyum sinıflamasina göre enerji ve besin ögesi alım düzeyleri değerlendirildiğinde; yüksek uyum gösterenlerin $B_{2}$ vitamini, folik asit, potasyum ve magnezyum alımının anlamlı olarak daha yüksek, sodyum alımlarının ise anlamlı olarak daha düşük olduğu bulunmuştur $(p<0.05)$. Ayrıca kadın bireylerde yüksek uyum gösteren bireylerin C vitamini, kalsiyum ve fosfor alımının düşük uyum gösteren bireylerden anlamlı olarak yüksek olduğu, erkek bireylerde ise posa ve çinko tüketiminin anlamlı olarak yüksek olduğu belirlenmiştir ( $\mathrm{p}<0.05)$ (Tablo 5).

\section{TARTIŞMA}

$\mathrm{Bu}$ çalışmada yaşlı hipertansiyon hastası bireylerin, DASH diyetine uyumlarının belirlenmesi ve DASH diyetine uyum ile antropometrik ölçümler, diyetle alım ve kan basıncı arasındaki ilişkinin değerlendirilmesi hedeflenmiştir. Çalışmaya katılan bireylerin DASH diyetine uyumunun düşük olduğu bulunmuştur. Benzer bir araştırmada eğitim durumu daha iyi olan kadın bireylerin DASH diyetine uyumlarının daha yüksek olduğu belirtilmiştir (18). Bu çalışmada da bireylerin çok az bir kısmına hastalıkları ile ilgili beslenme önerisi yapılmış olması ve büyük bir çoğunluğunun eğitim düzeyinin düşük olması DASH diyetine uyumun düşük olmasına etki etmiş olabilir.

$\mathrm{Bu}$ çalışmada DASH diyetine uyum ile kan basincı arasında herhangi bir ilişki olmadığı görülmüştür. Yapılan benzer çalışmalarda elde edilen sonuçlar farklılık göstermektedir $(15,17,19,20)$. DASH diyetine uyum ile kardiyovasküler risk faktörleri ve kan basıncı ilişkisinin incelendiği bir çalışmada, DASH diyetine daha düşük uyum gösteren bireylerin hem SKB ve hem de DKB değerlerinin anlamll olarak daha yüksek olduğu bulunmuştur (15). Mokhtari et al. (20)'un çalışmasında, DASH diyeti skoru ile DKB arasinda anlaml negatif korelasyon saptanırken, SKB ile arasında istatistiksel açıdan anlamlı olmayan negatif korelasyon saptanmıştır (20). Harrington et al. (21) tarafından yapılan başka bir çalışmada ise DASH 


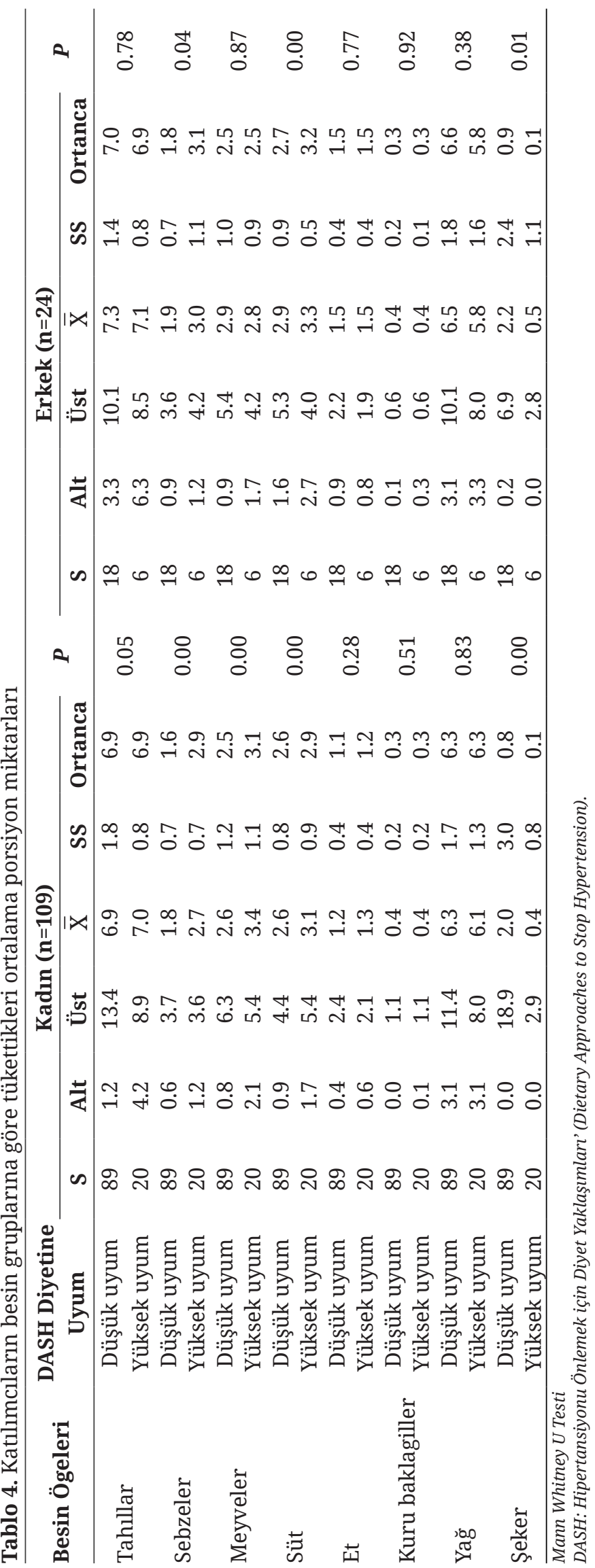

diyetine uyum arttıkça SKB değerinin anlamlı şekilde düştüğü belirtilmiş ancak Staffileno et al. (19)'un çalışmasında DASH diyeti ile kan basıncı arasında bir ilişki bulunmamıştır. Başka bir çalışmada, DASH diyetine uzun süreli uyumun kan basıncında azalma sağlamadığı ve hipertansiyon insidansını azaltmadığı bulunmuştur (22). Bu çalışmada DASH diyetine uyum ile kan basıncı arasında ilişki bulunamamasının, örneklem hacminin küçük olması, DASH diyetine uyumun örneklem genelinde düşük olması ve antihipertansif tedaviye bağlı olarak bireylerin kan basıncı değerlerinin genel olarak normale yakın olmasından kaynaklanabileceği düşünülmektedir.

DASH diyeti toplam yağ, doymuş yağ ve kolesterol alımının sınırlandırıldığı; potasyum, magnezyum, kalsiyum ve diyet posası bakımından zengin bir örüntüdür $(8,9)$. Çalışma sonucunda mikro besin öğeleri ile ilgili bulunan sonuçlar DASH diyetinin özellikleri ile uyumlu olup ayrıca yüksek uyum gösteren bireylerin düşük uyum gösteren bireylerden anlamlı şekilde yüksek sebze ve meyve tüketimi ile de örtüşmektedir $(\mathrm{p}<0.05)$. DASH diyetine uyum ile mikro besin ögesi alımlarının değerlendirildiği bir çalışmada, bu çalışma ile benzer şekilde DASH diyetine yüksek uyum gösteren grubun, düşük uyum gösteren gruba göre anlamlı olarak daha fazla kalsiyum, potasyum ve magnezyum aldığı saptanmıştır (15). Diğer bir çalışmada ise DASH skoru arttıkça lif, fosfor, kalsiyum, E vitamini ve C vitamini alımının arttığ belirtilmiştir (9). Bunlara ek olarak bu çalışmada DASH diyetine yüksek uyum gösteren grupta hem kadın hem de erkek bireylerde süt tüketimi istatistiksel olarak anlamlı şekilde yüksek $(p<0.05)$, şeker tüketim miktarları ise düşük uyum gösteren katılımcılara göre anlamlı olarak daha düşüktür $(\mathrm{p}<0.05)$. Yapılan benzer çalışmalarda da DASH diyetine yüksek uyum gösteren bireylerin meyve, sebze, düşük yağlı süt-süt ürünleri, tam tahıllar, yağlı tohum ve kurubaklagil tüketimlerinin DASH diyetine düşük uyum gösteren bireylere göre anlamlı olarak daha yüksek olduğu saptanmıştır. Ayrıca, DASH diyetine yüksek uyum gösteren bireylerin şekerli içecekler, tatlılar, kırmızı/ işlenmiş et tüketimlerinin DASH diyetine düşük uyum 


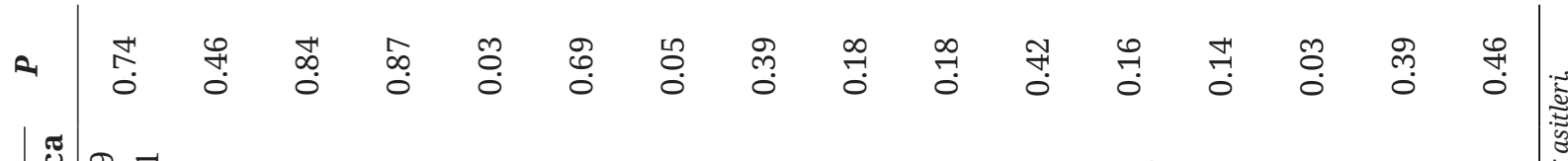
莺 矛

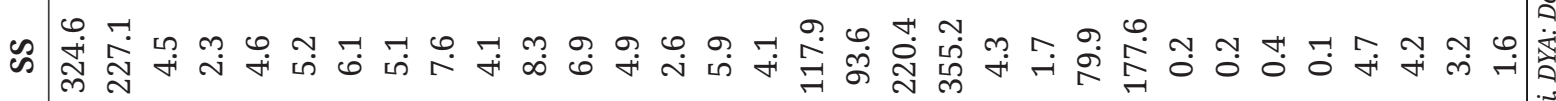

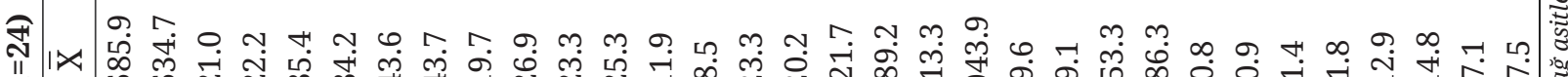
IJ

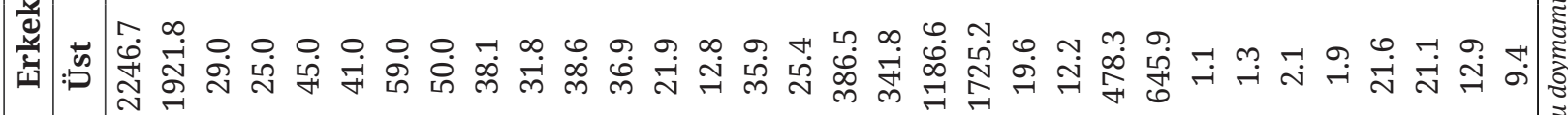

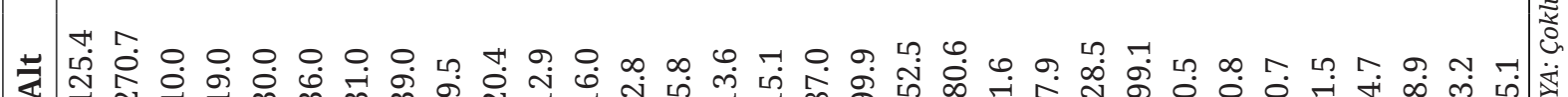

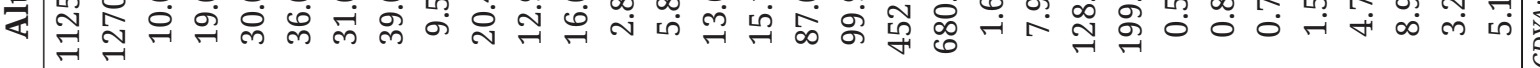

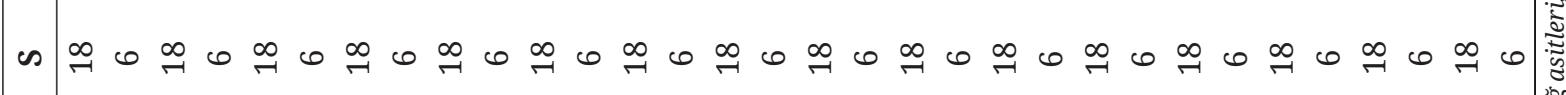

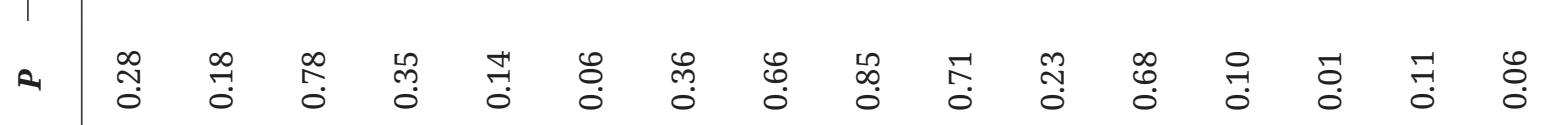
苞 人 n m

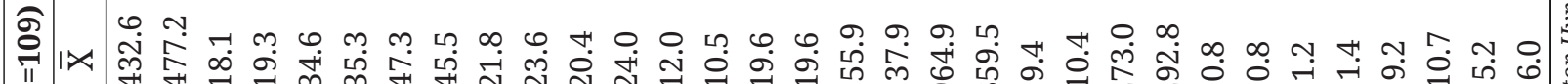

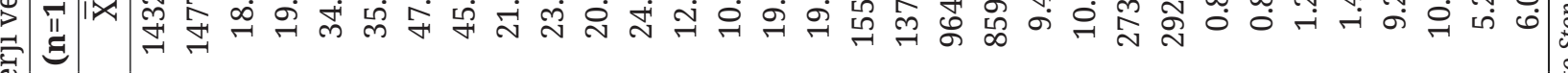

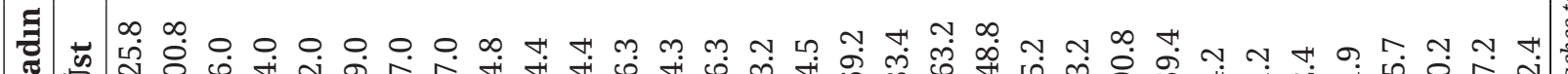

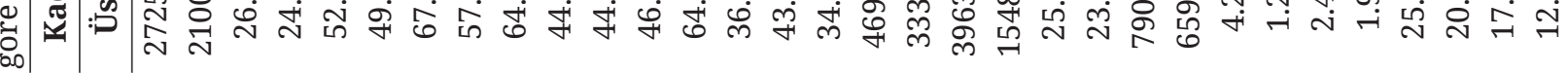

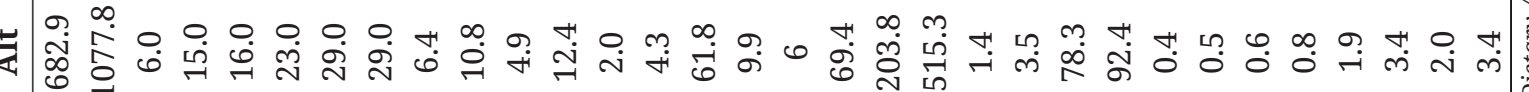
ฌ 고 ๖ 


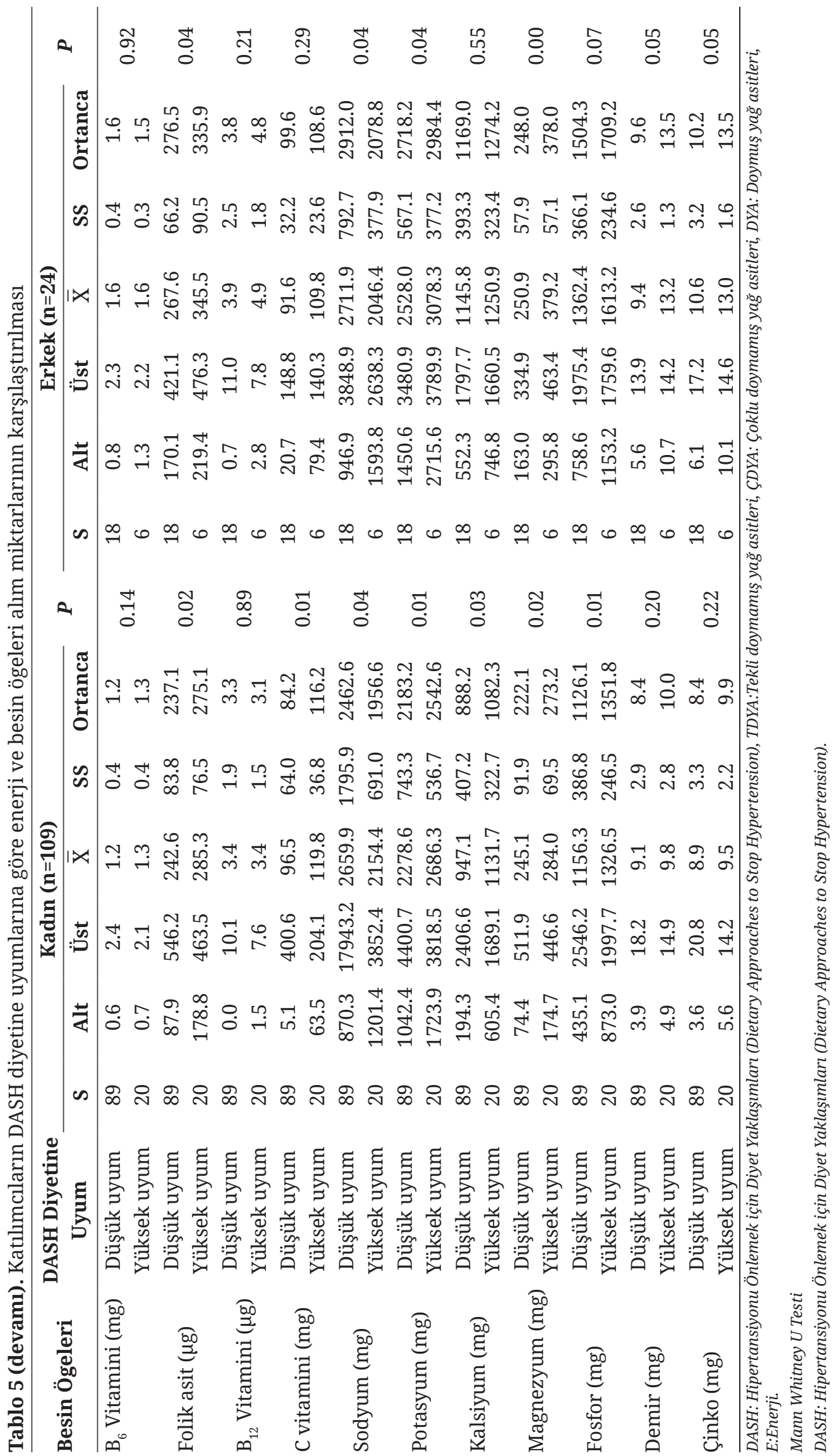


gösteren bireylere göre anlamlı olarak daha düşük olduğu görülmüştür $(9,20,23)$. DASH diyeti yüksek sebze, meyve, kurubaklagil, yağlı tohum içeriğinden dolayı kalsiyum, potasyum, magnezyumdan zengin bir diyettir. Bu nedenle bu çalışmada, diğer çalışmalara $(9,20,23)$ benzer şekilde yüksek uyum gösteren grubun bu besin ögelerini daha çok tükettiğinin bulunması beklenen bir sonuçtur.

DASH diyetindeki hedeflenen sodyum alımı 2300 mg/gün'dür. Bu çalışmada günlük sodyum alımları incelendiğinde; DASH diyetine uyumu düşük olan grubun sodyum alımının önerilen değerin üzerinde olduğu, yüksek uyum gösteren grupta ise önerilenin altında olduğu bulunmuştur $(\mathrm{p}<0.05)$. Neves et al. (15)'un çalışmasında, yapılan bu araştırmadan farklı olarak DASH diyetine yüksek uyum gösteren grubun sodyum alımlarının, düşük uyum gösteren gruba göre anlamlı olarak daha yüksek olduğu saptanmıştır.

DASH diyetine uyumun antropometrik ölçümler ile ilişkisi incelendiğinde; hem kadın hem de erkek bireylerde vücut ağırlığındaki artışın DKB değerinde artışla ilişkili olduğu bulunmuştur ( $\mathrm{p}<0.05)$. Bunlara ek olarak vücut ağırlığı artışının kan basıncı üzerindeki olumsuz etkisi pek çok yayında vurgulanmış olup $(24,25)$, vücut ağırlığındaki artışın DKB değerinde artışa neden olması şaşırtıcı değildir. Ben-Dov et al. (26)’un yaptığı benzer bir çalışmada, bireylerin başlangıçtaki SKB değerleri ile vücut ağırlıkları arasında anlamlı pozitif bir korelasyon olduğu, Akman ve ark. (27)'nın yaptığı çalışmada ise, BKİ ve bel çevresi ile SKB ve DKB değerleri arasında anlamlı ancak, çok zayıf bir korelasyon olduğu saptanmıştır. Yapılan başka bir çalışmada, BKİ ile DASH skoru arasında istatistiksel olarak anlamlı negatif korelasyon olduğu belirtilmiş (28), bir diğer çalışmada ise yüksek DASH skoruna sahip olan kadınların, BKİsinin anlamlı şekilde daha düşük olduğu vurgulanmıştır (9).

$\mathrm{Bu}$ çalışmanın ilk üç sınırlılığı örneklem sayısının küçük olması, örneklemdeki kadın-erkek dağılımının ve DASH diyetine uyum dağllımının dengesiz olmasıdır. Daha büyük ve dengeli bir örneklemle farklı sonuçlar elde edilmesi mümkün olabilir.
Diğer bir sınırlılık ise hastalar tarafindan kullanılan hipertansiyon ilacının türünün, doz ve miktarının detaylı olarak sorgulanmamasıdır. Bu durum DASH diyetine uyumun kan basincı üzerindeki etkisinin yorumlanmasını zorlaştırmıştır. Ayrıca kan basıncı ölçümü sadece tek bir gün yapılmıştır. Kan basıncının farklı günlerde ölçülerek ortalamasının alınması ile farklı sonuçlar elde edilmesi mümkün olabilir.

Sonuç olarak hipertansiyon hastası yaşlı bireylerin DASH diyetine uyumlarının düşük olduğu ve yüksek uyumun kan basıncına etkisinin olmadiğı bulunmuştur. Ancak vücut ağırlığındaki artışın DKB düzeyinde artışla ilişkili olduğu görülmüştür. $\mathrm{Bu}$ hasta grubunda diyete uyumun genel olarak düşük olmasının, DASH diyetinin olumlu etki gösterememiş olmasında rolü olabileceği düşünülmektedir. Hipertansiyon hastalarında DASH diyetine uyumun hipertansiyon belirteçleri üzerindeki etkisi farmakolojik olmayan tedavinin etkinliğini görmek açısından önemli olup, daha büyük örneklem büyüklüğüne sahip farklı çalışmalarla detaylı olarak incelenmesi, yaşam tarzı değişikliğinin önemli bir parçası olan sağlıklı beslenmenin önemini vurgulamak açısından yararlı olacaktır.

Çıkar çatışması - Conflict of interest: Yazarlar çıkar çatışması olmadığını beyan ederler. - The authors declare that they have no conflict of interest.

\section{KAYNAKLAR}

1. World Health Organization. World Report on Ageing and Health: Healthy Ageing, Luxemburg: World Health Organization; 2015. p.246.

2. Sönmez S, Temel BA, Vural KB. Yaşlılarda beslenme sağlığını etkileyen faktörler: Balıkesir İli Göçmen Konutları Beldesi örneği. Aile ve Toplum Dergisi, 2007;(12):33-46.

3. World Health Organization. Global Status Report on Noncommunicable Diseases 2014. Switzerland: World Health Organization; 2014. 280

4. Üner S, Balcılar M, Ergüder T. Dünya Sağlık Örgütü Türkiye Ofisi. Türkiye Hanehalkı Sağlık Araştırması: Bulaşıcı Olmayan Hastalıkların Risk Faktörleri Prevalansı 2017 (STEPS). Ankara: World Health Organization; 2018. s.138. 
5. Conlin PR, Chow, D, Miller ER, Svetkey LP, Lin PH, Harsha DW, et al. The effect of dietary patterns on blood pressure control in hypertensive patients: results from the Dietary Approaches to Stop Hypertension (DASH) trial. Am J Hypertens. 2000;13(9):949-55.

6. Saneei P, Abargouei SA, Esmaillzadeh A, Azadbakht L. Influence of Dietary Approaches to Stop Hypertension (DASH) diet on blood pressure: A systematic review and meta-analysis on randomized controlled trials. Nutr Metab Cardiovasc Dis. 2014;24:1253-61.

7. Ndanuko RN, Tapsell LC, Charlton KE, Neale EP, Batterham MJ. Dietary patterns and blood pressure in adults: a systematic review and meta-analysis of randomized controlled trials. Adv Nutr. 2016;7(1):76-89.

8. Kwan MWM, Wong MCS, Wang HHX, Liu LQK, Lee SLC, Yan YPB. Compliance with the Dietary Approaches to Stop Hypertension (DASH) Diet: A systematic review. PLOS ONE 2013;8(10):e78412.

9. Folsom RA, Parker DE, Harnack JL. Degree of concordance with DASH diet guidelines and incidence of hypertension and fatal cardiovascular disease. Am J Hypertens. 2007;20:225-32.

10. Pickering TG, Hall JE, Appel LJ, Falkner BE, Gravses J, Hill MN, et al. Recommendations for blood pressure measurement in humans and experimental animals part 1: Blood Pressure Measurement in Humans A Statement for Professionals from the Subcommittee of Professional and Public Education of the American Heart Association Council on High Blood Pressure Research. Circulation. 2005;111:697-716.

11. Türkiye Beslenme Rehberi (TÜBER). Pekcan G, Şanlıer N, Baş M, Başoğlu S, Acar Tek N, editörler. Ankara: T.C. Sağlık Bakanlığı Yayın No:1031: 2015. s.54.

12. Meseri R, Uçku R, Ünal B. Waist:height ratio: a superior index in estimating cardiovascular risks in Turkish adults Public Health Nutr. 2013;17(10):224652.

13. Rakıcıoğlu N, Tek AN, Ayaz A, Pekcan G. Yemek ve Besin Fotoğraf Kataloğu: Ölçü ve Miktarları, 3. Baskı, Ankara: Ata Ofset Matbaacılık; 2012.s.132.

14. Beslenme Bilgi Sistemi (BeBiS). Versiyon 7.0, 2017, İstanbul.

15. Casanova MA, Medeiros F, Oigman W, Neves FM. Low concordance with the DASH plan is associated with higher cardiovascular risk in treated hypertensive patients. ISRN Hypertens. 2014;14:1-8.

16. Mellen BP, Gao KS, Vitolins ZM, Goff CD. Deteriorating dietary habits among adults with hypertension. Arch Intern Med. 2008;168(3):308-14.

17. Leon-Munoz LM, Guallar-Castillon P, Graciani A, Lopez-
Garcia E, Mesas EA, Taboada MJ. Dietary habits of the hypertensive population of Spain: accordance with the DASH diet and the Mediterranean diet. J Hypertens. 2012;30:1373-82.

18. Fitzgerald KC, Chiuve SE, Buring JE, Ridker PM, Glynn RJ. Comparison of associations of adherence to a Dietary Approaches to Stop Hypertension (DASH)-style diet with risks of cardiovascular disease and venous thromboembolism. J Thromb Haemost. 2011; 10(2):18998.

19. Staffileno AB, Tangney CC, Wilbur J, Marquez XD, Fogg L, Manning A. Dietary Approaches to Stop Hypertension patterns in older Latinos with or at risk for hypertension. J Cardiovasc Nurs. 2013;28(4):338-47.

20. Mokhtari Z, Nasrollahzadeh J, Miri R, Rashidkhani B, Hosseini S. Relationship between dietary approaches to stop hypertension score and presence or absence of coronary heart diseases in patients referring to Imam Hossein Hospital, Tehran, Iran. ARYA Atheroscler. 2013;9(6):319-25.

21. Harrington MJ, Fitzgerald PA, Kearney MP, McCarthy CJV, Madden J, Browne G. DASH diet score and distribution of blood pressure in middle-aged men and women. Am J Hypertens. 2013;26(11):1311-20.

22. Jiang J, Liu M, Troy LM, Bangalore S, Hayes RB, Parekh N. Concordance with DASH diet and blood pressure change: results from the Framingham Offspring Study (1991-2008). J Hypertens. 2015;33(11):2223-30.

23. Levitan EB, Wolk A, Mittleman MA. Relation of consistency with the dietary approaches to stop hypertension diet and incidence of heart failure in men aged 45 to 79 years. Am J Cardiol. 2009;104(10):1416-20.

24. Kotchen TA. Obesity-related hypertension: epidemiology, pathophysiology, and clinical management. Am J Hypertens. 2010;23(11):1170-8.

25. Nurdiantami Y, Watanabe K, Tanaka E, Pradono J, Anme T. Association of general and central obesity with hypertension. Clin Nutr. 2018;37(4):1259-63.

26. Ben-Dov I, Grossman E, Stein A, Shachor D, Gaides M. Marked weight reduction lowers resting and exercise blood pressure in morbidly obese subjects. Am J Hypertens. 2000;13(3):251-5.

27. Akman M, BudakŞ, Kendir M. Genel dahiliye polikliniğine başvuran hastalarda obezite sıklığı ve ilişkili sağlık problemleri. Marmara Med J. 2004;17(3):113-20.

28. Beasley J, Viswanathan S, Wylie-Rosett J. Associations between change in DASH diet scores and CVD risk factors in the PREMIER Trial. FASEB J. 2014;28(1):Abstract number 369.1. 